\title{
ANIMAL MODEL OF RENAL ISCHEMIC INJURY, AND CHLORPROMAZINE PROTECTOR EFFECT, EVALUATE BY TC-99M-MAG ${ }_{3}$ DYNAMIC RENAL SCAN ${ }^{1}$
}

\author{
Whemberton Martins de Araújo ${ }^{2}$ \\ Silvio Tucci Júnior ${ }^{3}$ \\ Roberto S. Costa ${ }^{4}$ \\ Ricardo Aparecido Ferreira ${ }^{5}$ \\ Maria de Lourdes Pozza ${ }^{6}$ \\ Sebastião Assis Mazzetto ${ }^{7}$ \\ Paulo Alves ${ }^{7}$ \\ Adauto José Cologna ${ }^{8}$ \\ Antonio Carlos Pereira Martins ${ }^{8}$
}

\begin{abstract}
Acute tubular necrosis (ATN) is a major complication of kidney transplantation, so as of urologic and vascular surgeries. In transplantation, although organ perfusion with proper solution are feasible and at least partially effective, new approaches remains needed to avoid lost of graft function due to ischemic insults, and by this way, chlorpromazine may play this hole. Sixteen male rats were evaluated by scintigraphy (dynamic renal scan with Tc-99m-MAG 3 ), before and after surgically promote ischemia of left kidney. Animals were divided in 3 groups: Group A (control) without ischemic insult; Group B (ischemia without chlorpromazine) and Group C (ischemia with chlorpromazine). Group B demonstrated marked decreased of left renal function, compared with itself (right kidney; $p<0,001$ ) and compared with groups $\mathrm{A}$ and $\mathrm{C}$ (both $\mathrm{p}<0,001$ ). No statistically observations was noted in group A, that makes sure of non-error source of surgical procedure lonely $(\mathrm{p}<0,05)$. Nevertheless mild decrease of left renal function was observed in some animals of group $\mathrm{C}$, these appointments were not statistically significant $(p<0,05)$. Further studies may prove, in the future, its usefulness in humans, specially concerning kidney
\end{abstract}

transplantation. Available from URL: http:// www.scielo.br/acb

Key-Words - Nuclear Medicine, Tc-99m-MAG3, Ischemia, Kidney, Rats.

\section{INTRODUCTION}

Renal ischemic injury is the most common cause of acute renal failure in adults. Acute Tubular Necrosis (ATN) following ischemic injury is relatively common in vascular and urologic surgical procedures, leading to temporary renal failure, and otherwise, to permanent renal insufficiency, and so, hemodialysis. Another usual situations are ATN following kidney transplantation, and cortical atrophy related to urinary obstruction ${ }^{1-3}$.

ATN is characterized for an oliguric phase, along 48 hours since after ischemic injury, and followed by progressive recovery of renal function, usually until 714 days, with marked polyuria. In animals, these facts may be produced through ischemia during 40-60 minutes ${ }^{4}$. Although just a few tubular cells reach necrosis, installed tubular dysfunction is significant, reducing glomerular filtration rate (GFR), that is the main event related to ATN, specially due to afferent vasoconstriction, "back leak" effect, and tubular obstruction ${ }^{2}$.

1 Trabalho realizado na Hospital das Clínicas da Faculdade de Medicina de Ribeirão Preto da Universidade de São Paulo (HCFMRP-USP).

2 Médico Assistente, Seção de Medicina Nuclear

3 Professor Doutor, Departamento de Cirurgia e Anatomia

4 Professor Doutor, Departamento de Patologia e Medicina Legal

5 Tecnólogo, Seção de Medicina Nuclear

6 Auxiliar de Enfermagem, Seção de Medicina Nuclear

7 Técnicos especializados, Seção de Cirurgia Experimental

8 Docentes do Departamento de Cirurgia e Anatomia 
Nowadays, during kidney transplantation, preservation of donor organ is done through arterial perfusion with solutions similar to intra-cellular environment, under low temperature. Hypothermia is largely used to diminish cell metabolic activity ${ }^{1}$. These solutions also may promote protection while irrigation is use "in situ", however, with need of arterial and venous venoclysis ${ }^{5}$, that justifies the search for a protective substance that might be use by intravenous access, as an easier way ${ }^{6,7}$.

Farber (1982) first described benefits of chlorpromazine previous infusion in tissues submitted to ischemia in reperfused mouse livers ${ }^{8}$. In our environment, chlorpromazine has already been used to establish an ischemic compound in extra-hepatic cholestasis in rats 9 . Faced these facts, we propose with this research to experimentally evaluate the existence of chlorpromazine protective effect in kidneys submitted to ischemic injury.

\section{METHODS}

\section{Animals:}

We used sixteen male Wister rats, $(350 \pm 33$ grams), divided into three groups:

Group A: Control, without ischemia (4 animals)

Group B: Ischemia, without chlorpromazine (7 animals)

Group C: Ischemia, with chlorpromazine (5 animals)

\section{Dynamic renal scan:}

We choose the scintigraphic dynamic renal

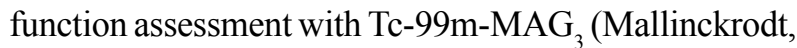
Netherlands), a worldwide used renal tracer, excreted almost exclusively by tubular secretion $(98 \%)$. The procedure was performed in all animals, before any surgical intervention (basal study).

Animals were anesthetized with intra-peritoneal thionembutal. Intending to create a proper venous access, we use neonatal umbilical catheter into left jugular vein. Animals were leaded back-faced to LEAP (low energy all purpose) collimator, with limbs fixed by adhesives patches over a wood rigid and thin sheet. Prior to exam, it was infused IV $0,5 \mathrm{~mL}$ of saline $0,9 \%$ solution, very slowly, to assure proper hydration. After make sure that kidneys and bladder were in the gamma camera field of view, $500 \mathrm{mCi}$ of Tc-99m-MAG 3 in $0,1 \mathrm{~mL}$ was infused through the jugular access, and so, starting acquisition with 2 groups, first one a perfusion phase (1 image each 3 seconds, along 1 minute), and a second function phase (1 image each 60 seconds along a half hour), $140 \mathrm{keV}$ photo peak, $15 \%$ window of acceptance, Siemens AG Orbiter Gamma-Camara. By this way, it was made sure of normal and symmetrical function of both kidneys.

\section{Surgical procedure:}

All animals, after proper anesthesia with intraperitoneal thionembutal, were surgically accessed through median longitudinal laparotomy, for identification and isolation of left renal artery.

Group A had just isolated its left renal artery, without no ischemic injury, and stand by this way along 1 hour, with incision properly closed at the end. Nothing was done to right kidney in all groups.

Group B, same way as group A, had left renal artery isolated, but completed mechanically occluded (metallic clip), also along one hour.

On the other hand, group $\mathrm{C}$ also had its left renal artery occluded for one hour, but with prior fifteen minutes $3 \mathrm{mg} / \mathrm{kg}$ IV chlorpromazine IV administration.

After 24 hours, all animals repeated renal scan, to access renal function changes or maintenance. Further, both kidneys were carefully removed, while animal still alive and anesthetized, and each kidney sectioned transversally along its longitudinal axis, at the level of the renal pelvis, and immediately stored completely immersed into tamponade formol. After, animals were sacrificed, while anesthetized.

Dynamic scan analysis was made by split renal function assessment, by renogram under slope area, with integration limits of one and two minutes, giving a reasonable approach of cortical function, without marked urine interference. By this way, it was calculated the percentual split uptake in all renograms. Means of split uptake, in basal and 24 hours studies of all three groups, were registered and statistically analyzed.

\section{RESULTS}

The mean split uptake in all basal studies was $(46 \pm 1,4) \%$ for left kidney, and $(54 \pm 1,4) \%$ for right kidney, in all groups. Significance of changes/ maintenance in relative function of kidneys was tested by $\mathrm{T}$ Student test (table 1). 
Table 1 - Arithmetic means and standard deviations of split kidney functions, in all groups. LK b: Left Kidney (basal); RK b: Right Kidney (basal); LK 24h: Left Kidney 24 hours; RK 24h: Right Kidney 24 hours.

\begin{tabular}{ccccc}
\hline Groups & LK 24h & LKb & RK 24h & RK b \\
\hline Group A & $(46 \pm 0,5) \%$ & $(54 \pm 0,5) \%$ & $(47,5 \pm 2,5) \%$ & $(52,5 \pm 2,5) \%$ \\
Group B & $(46 \pm 1,7) \%$ & $(54 \pm 1,7) \%$ & $(25 \pm 8,2) \%$ & $(75 \pm 8,2) \%$ \\
Group C & $(46 \pm 1,2) \%$ & $(54 \pm 1,2) \%$ & $(44 \pm 5,5) \%$ & $(56 \pm 5,5) \%$ \\
\hline
\end{tabular}

Basal functions in both kidneys were statistically similar $(\mathrm{p}<0,05)$, in all groups. In group $\mathrm{A}$, there was no significant change between basal and 24 hours studies $(\mathrm{p}<0,05)$. Nevertheless little changes might be visually observed in-group $C$ (between basal and 24 hours steps), these changes were not statistically significant $(p<0,05)$. Marked decrease of left renal function was noted in 24 hours studies in-group B, comparatively with its basal phase $(p<0,001)$. Group $\mathrm{B}$ compared with itself (left kidney compared with right one) also demonstrated significant changes $(\mathrm{p}<0,001)$. By the same matter, no significant change was noted in groups $A$ and $C(p<0,05)$.
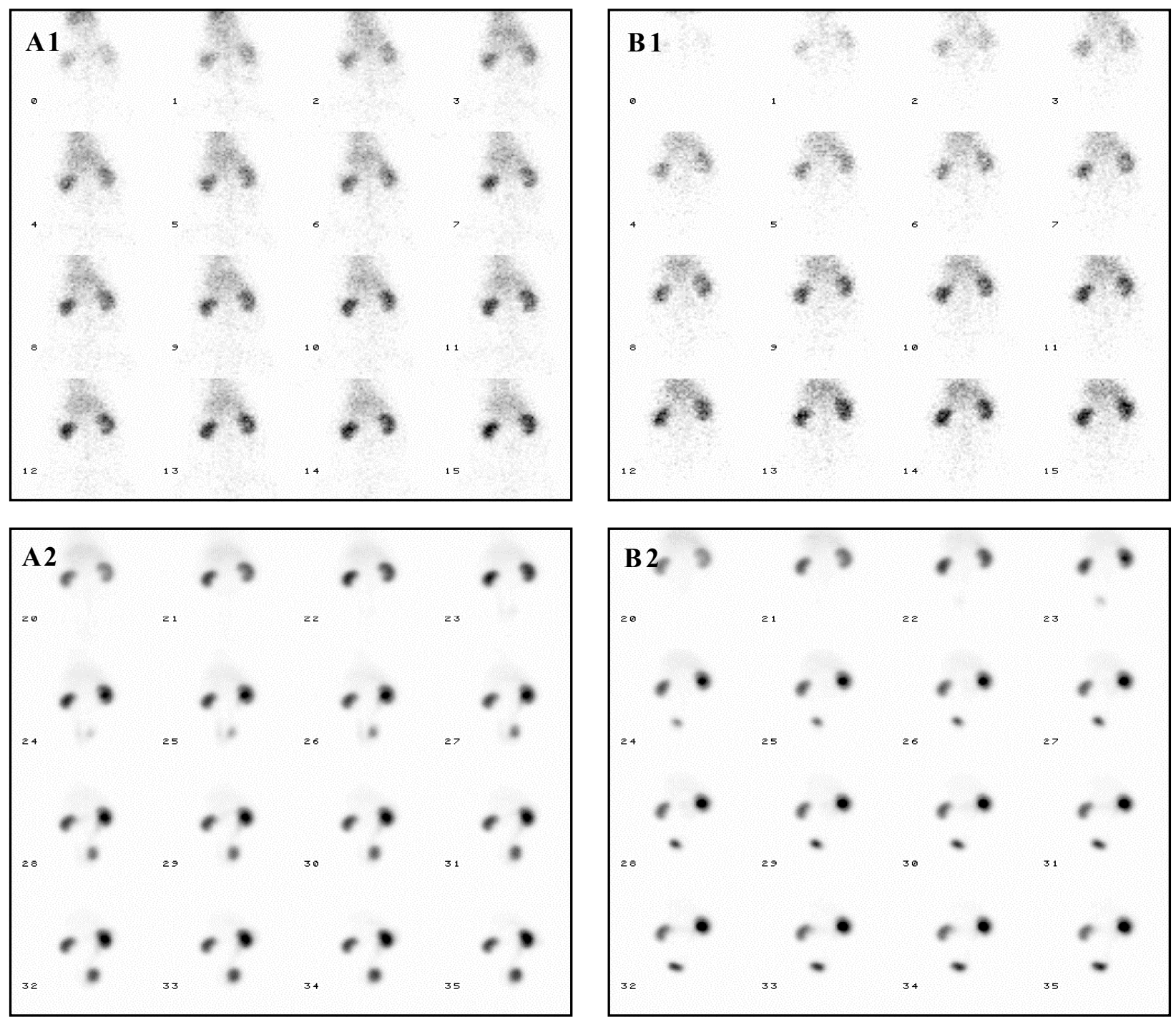

Figure 01 - Control Group (Group A). Basal study (A1 and A2), with perfusion (A1) and function (A2) phases, showing preserved function in both kidneys, so as pervious urinary pathways (back view). Second study 24 hours after surgery (B1 and B2), without ischemia, and so, without pattern changes. 

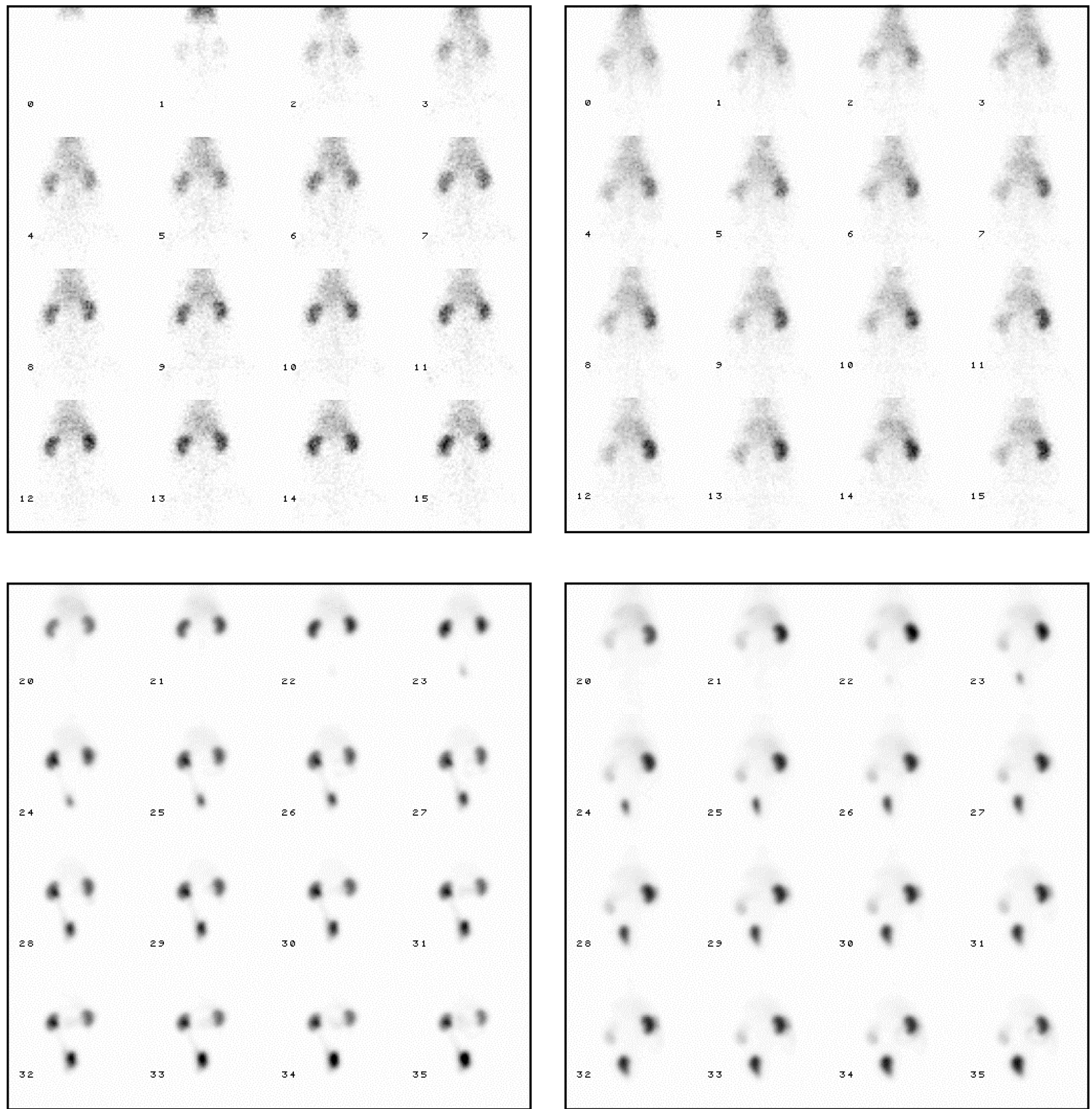

Figure 02 - Ischemia without chlorpromazine (group B). Basal study (A1 and A2) with normal perfusion and functional pattern bilaterally, and 24 hours study (B1 and B2) showing marked and statistically significant decreased left renal function, post ischemic insult $(\mathrm{p}<0,001$; arrow).

\section{DISCUSSION AND CONCLUSIONS}

Impressive and statistically proved differences between Group B/Group C and Group B/Group A testify the efficiency of Chlorpromazine in maintain (even if almost completely) renal function after a significant ischemic injury. No changes in group A make sure that surgical procedure lonely is not a significant error variable.
Further considerations, as follow-up pattern and histological correlation, are appointments that are already under evaluation by our research group, as a continuation of the presenting protocol.

In the future, its usefulness in kidney transplantation in humans should be tested by further studies. 

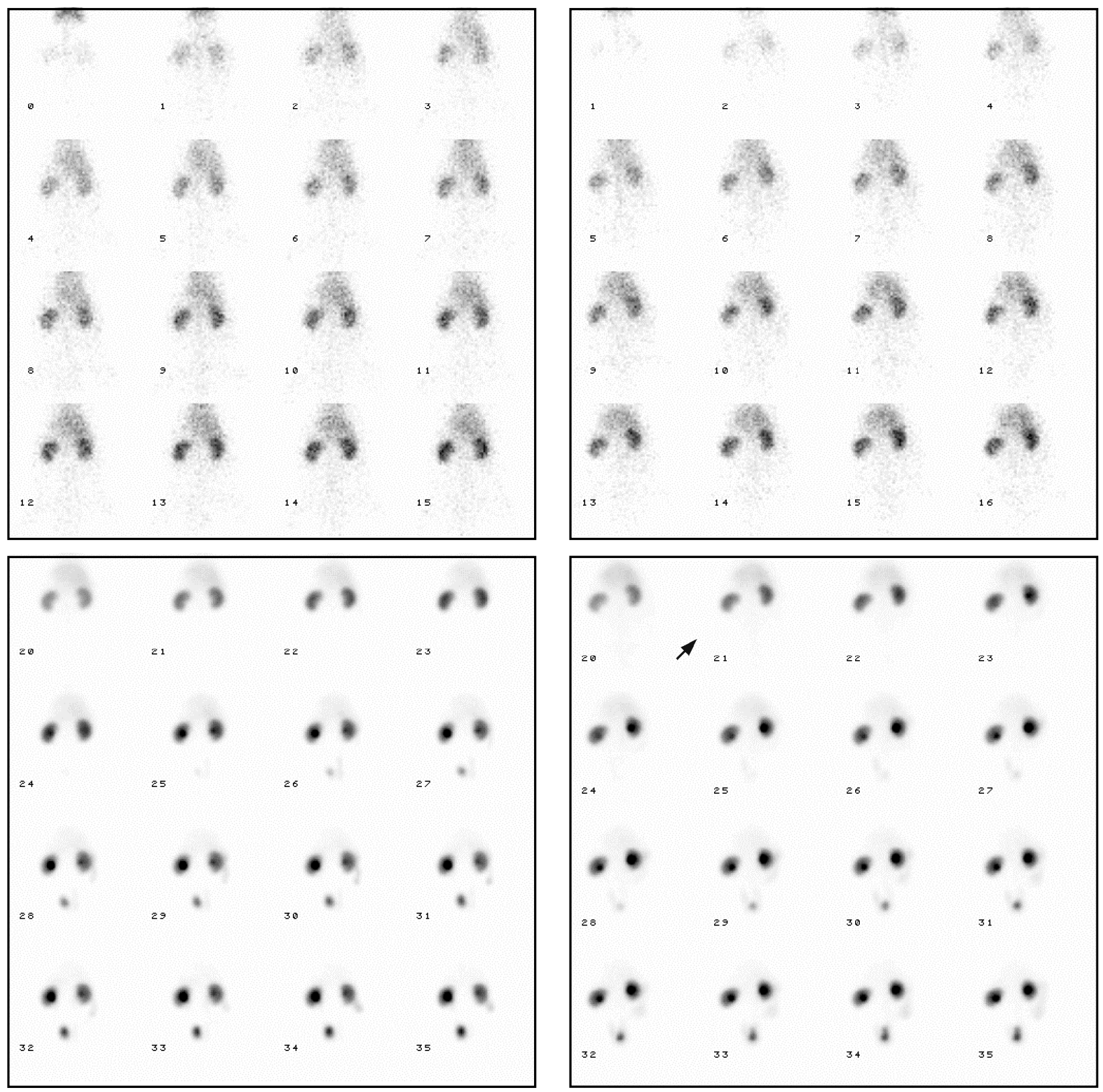

Figure 03 - Ischemia with chlorpromazine (group C). Basal study (A1 and A2), with normal pattern, and 24-hour phase (B1 and B2), with just mild decrease of left renal function (not statistically significant; $\mathrm{p}<0,05$; arrow).

\section{REFERENCES}

1. Farber JL, Chien KR, Mittnacht S. The pathogenesis of irreversible cell injury in ischemia. Am J Pathol 1981; 102: 271-81.

2. Sutton TA, Molitoris BA. Mechanisms of cellular injury in ischemic acute renal failure. Sem Nephrol 1998; 18: 490-7.

3. Brezis M. Cellular mechanisms of acute ischemic injury in the kidney. Annu Rev Med 1993; 44:27-37.

4. Moran SM, Myers BD. Pathophysiology of protracted acute renal failure in man. J Clin Invest 1985; 76: 1440-8.

5. Andrews PM; Coffey AK. Protection of kidneys from acute renal failure resulting from normotermic ischemia. Lab Invest, 1983; (1):87-93

6. Ametani MS, Southard JH, Belzer FO. Importance of glutathione and adenosine in cold storage of the kidney. Transplant Proc 1990; 22: 469-70.
7. Cejalvo D, Lloris-Carsi JM, Toledo-Pereyra LH, Calvo MA. Effect of adenosine and allopurinol on liver ischemiareperfusion. Transplant Proc 1993; 25: 3023-4.

8. Farber JL. Biology of disease: membrane injury and calcium homeostasis in the pathogenesis of coagulative necrosis. Lab Invest, 1982; 47: 114-23.

9. Castro e Silva Jr. O, Ceneviva R, Roselino JES. Portal flow and mitochondrial function during extrahepatic cholestasis. Braz J Med Biol Res; 1988; 21: 637-40.

\section{Endereço para correspondência:}

Whemberton Martins de Araújo

Seção de Medicina Nuclear, Hospital das Clínicas da Faculdade de Medicina de Ribeirão Preto, Universidade de São Paulo (HC-FMRP-USP).

Campus Monte Alegre, s/n, Ribeirão Preto/SP-Brasil e-mail: whemberton@hcrp.fmrp.usp.br 